\title{
Lessons learned from a pilot implementation of physical activity recommendations in axial spondyloarthritis exercise group therapy
}

Anne-Kathrin Rausch Osthoff ${ }^{1,2^{*}}$, Theodora P. M. Vliet Vlieland ${ }^{2}$, André Meichtry ${ }^{1}$, Leti van Bodegom-Vos ${ }^{3}$, Beatrice Topalidis ${ }^{4}$, Stefan Büchi ${ }^{5}$, Irina Nast ${ }^{1}$, Adrian Ciurea ${ }^{6}$ and Karin Niedermann ${ }^{1}$

\begin{abstract}
Background: The Ankylosing Spondylitis Association of Switzerland (SVMB) aimed to implement physical activity recommendations (PAR) within their exercise groups (EGs). The PAR promote exercise in all fitness dimensions at the correct dose. To implement the PAR within EGs, they were translated into a new EG concept with five key activities: (a) training for supervising physiotherapists (PTs), (b) correctly dosed exercises in all fitness dimensions, (c) exercise counselling, (d) bi-annual fitness assessments, and (e) individual exercise training, in addition to EG. All these activities were realized in close coordination with SVMB management.
\end{abstract}

Objectives: To analyse the implementation success by evaluating adherence/fidelity, feasibility, and satisfaction at the patient, PTs, and organisational level.

Methods: The five key activities of the new EG concept were developed, executed, and assessed after 6 months. The primary outcomes for implementation success were adherence of patients to the recommended exercise behaviour, self-reported by electronic diary; fidelity of PTs to the new concept, self-reported by diary; SVMB organisational changes. Secondary outcomes were feasibility and satisfaction with the new EG concept at all three levels. The tertiary outcome, to evaluate the effectiveness of PAR, was patient fitness, assessed through fitness assessments.

Results: 30 patients with axSpA (ten women, mean age $58 \pm 9$ years) and four PTs (three women, mean age $46 \pm 9$ years) participated. The patients' self-reporting of adherence to the PAR was insufficient (43\%), possibly due to technical problems with the electronic dairy. The PTs' fidelity to the new EG concept was satisfactory. On all levels, the new concept was generally perceived as feasible and useful for supporting personalised exercise.The frequency of exercise counselling and the fitness assessments was found by patients and PTs to be too high and rigid. Patients' cardiorespiratory fitness [ES $1.21(95 \% \mathrm{Cl} 0.59,1.89)]$ and core strength [ES $0.61(95 \% \mathrm{Cl} 0.18,1.06)$ ] improved over the 6 months.

Conclusions: The pilot implementation of PAR showed acceptance and satisfaction to be sufficient, thus confirming the need for evidence-based EGs, provided by a patient organisation in order to support active PA behaviour. However, adaptations are necessary to increase its feasibility for nationwide implementation.

\footnotetext{
*Correspondence: anne-kathrin.rausch@zhaw.ch

1 ZHAW, School of Health Sciences, Institute of Physiotherapy, Zurich

University of Applied Sciences, Katharina-Sulzer-Platz 9, 8401 Winterthur,

Switzerland

Full list of author information is available at the end of the article
}

(C) The Author(s) 2022. Open Access This article is licensed under a Creative Commons Attribution 4.0 International License, which permits use, sharing, adaptation, distribution and reproduction in any medium or format, as long as you give appropriate credit to the original author(s) and the source, provide a link to the Creative Commons licence, and indicate if changes were made. The images or other third party material in this article are included in the article's Creative Commons licence, unless indicated otherwise in a credit line to the material. If material is not included in the article's Creative Commons licence and your intended use is not permitted by statutory regulation or exceeds the permitted use, you will need to obtain permission directly from the copyright holder. To view a copy of this licence, visit http://creativecommons.org/licenses/by/4.0/. The Creative Commons Public Domain Dedication waiver (http://creativeco mmons.org/publicdomain/zero/1.0/) applies to the data made available in this article, unless otherwise stated in a credit line to the data. 
Trial Registration: SNCTP, SNCTP000002880. Registered 31 May 2018, https://www.kofam.ch/en/snctp-portal/search/0/ study/42491.

Keywords: Physical therapy, Ankylosing spondylitis, Assessment, Coaching, Counselling, Group exercise

\section{Introduction}

Patients with axial Spondyloarthritis (axSpA) have an increased risk of cardiovascular diseases [1]. In addition, evidence shows that axSpA has an impact on flexibility [2], balance [3], muscle strength [4], and cardio-respiratory capacity [5].

Exercise and effective drug treatment are recommended as the cornerstones of disease management $[6$, 7]. Indeed, the promotion of physical activity (PA) and specific exercise (cardiovascular, muscle strength, flexibility, and neuromotor exercise) should be an integral part of standard care throughout the course of disease [8]. Regarding cardiovascular exercise, evidence underpins that the appropriate intensity and frequency are relevant to reduce the risk of cardiovascular diseases in healthy people effectively; this might be valid for people with rheumatic and musculoskeletal diseases (RMDs) as well $[9,10]$. Furthermore, evidence shows that exercise according to public health recommendations for healthenhancing PA is effective, safe, and feasible in people with RMDs [11]. Consequently, PA recommendations should be implemented, establishing a standard for PA and exercise promotion and education of health professionals for effectively delivering PA promotion and exercise across Europe.

The Ankylosing Spondylitis Association of Switzerland (Schweizerische Vereinigung Morbus Bechterew, SVMB) decided to implement the PA recommendations within their exercise groups. It was further decided to involve the SVMB members who currently do not participate in exercise groups at a later stage of time.

Previously, the groups, each consisting of between 5 and 25 patients with axSpA, met weekly to conduct 45-60 min of spinal flexibility and strength exercises, mostly land-based, few water-based, or combined, under the supervision of a physiotherapist (PT). Health insurers refunded the costs for the attendance of these exercise groups.

The overall aim of this implementation project was to establish the PA recommendations for patients with axSpA participating in exercise groups to perform exercises regularly and adequately dosed [12]. The PA recommendations were translated into a new SVMB exercise group concept, named "moveSVMB" (an acronym for iMplementation Of physical actiVity rEcommendations in $S V M B$ ). It incorporated the following key implementation activities: (a) 2 days of training for supervising PTs, (b) exercises in all fitness dimensions, according to the exercise guidelines [13], (c) quarterly individual exercise counselling with a supervising PT to support more individual exercise training, (d) bi-annual fitness-assessments, and (e) individual exercise training in addition to group exercise. All implementation activities were closely coordinatedby SVMB management and study staff.

It is well known that the implementation of innovations in clinical routine is a great challenge $[14,15]$, requiring a planned and systematic approach with clear strategies. Knowledge does not necessarily lead to changed behaviour [16-18]. In this project, the implementation process was determined following the cyclical approach of Grol and Wensing' implementation of change model [19] and included the following steps (and publications): (A) analysis of the current clinical practice and settings (as briefly outlined above, [20]); (B) exploration of facilitators and barriers towards PA and exercise from the stakeholders' perspective, i.e. patients with axSpA, PTs and rheumatologists [21], including the patients' perspective on technology-based exercise (yet unpublished data); (C) development and application of a tailored implementation strategy; (D) pilot testing and adjustment of the applied strategy, and (E) nationwide implementation.

The aim of the present pilot implementation study was to perform steps $(C)$ and (D) and evaluate the adherence to recommended exercise behaviour on the levels of patients with axSpA, the fidelity to the new concept on the level of PTs, and the feasibility and satisfaction regarding the new concept, on the levels of patients, PTs and organisation. An additional objective was to investigate the effectiveness of PA recommendations at the level of patients. Furthermore, the long-term implementation fidelity was evaluated to gain lessons learned and inform the future nationwide implementation (step E).

\section{Methods}

The Standards for Reporting Implementation Studies (STaRI) checklist [22] were followed to report theimplementation steps (Additional file 1), as well as the recommendations for reporting implementation strategies [23]. The study was registered (SNCTP000002880) and approved by the ethical board of Canton Zurich (BASEC-Nr. 2018-00145). PTs and patients gave written informed consent. 


\section{Study design}

The pilot implementation study had a hybrid type 3 design [24]. It was executed from June (T0) to November 2018 (T1), with evaluations at T1 and at T2 (T2 after 1 year). An implementation strategy, nested implementation activities and evaluation procedures for each of the relevant target groups were developed, i.e. patients with axSpA, PTs, and SVMB management. For details refer to Table 1 and "Implementation strategy" section below. The outcomes and assessments used to evaluate the implementation strategy and the effectiveness of the PA recommendations on the level of patients with axSpA, are described in Table 2 and below in "Evaluations" section.

\section{Implementation strategy}

Targeting patients and PTs: the new exercise group concept "moveSVMB" A new EG concept encompassing the following key elements was introduced:

\section{a. Training of supervising PTs}

The supervising PTs attend a mandatory 2 days of training to learn how to apply the new concept within their exercise groups. The training consists of: gaining knowledge and awarenessof the general and EULAR PA recommendations and improving exercise counselling and motivational support skills. The monitoring of quality is performed by diary and peerinvolvement through regular exchange betweenthe PTs and study staff. Besides communication and psychological theory, PTs learn the practical use of the instrument PRISM (Pictorial Representation of Illness and Self Measure, described in Additional file 2) [25] and, behavioural change techniques, such as goal setting and strengthening self-efficacy using role plays. Furthermore, study staff and PTs discuss thestudy processes. During the pilot intervention a refresher event and regular support is provided, e.g. "help desk" for current issues.

b. Correctly dosed exercises in all fitness dimensions

PTs instruct and perform exercises in all fitness dimensions during the exercise group sessions. According to the current knowledge of exercise guidelines, the dosage of exercises follows the FITT (Frequency, Intensity, Type, Time) principles $[8,13]$. Patients are additionally informed about the importance and elements of adequate exercise through information provided by the SVMB (website, SVMB journal). Both activities enable patients to perform exercises alone.

\section{c. Individual and group exercise counselling}

PTs are asked to perform three individual exercise counselling sessions with each patient and at least three group interventions to improve patients PA behaviour.

An individual counselling session lasts about $30 \mathrm{~min}$. PTs are encouraged to use an empathic, supportive, yet directive counselling style, according to the principles of Motivational Interviewing [26]. PTs are asked to start each individual session by applying the PRISM, which is a visual-tactile instrument that fosters communication, collaboration and mutual confidence $[25,27]$. PRISM can also be used to get to know a person better, by defining dimensions relevant to his/her life and, thus, enhancing intrinsic motivation and self-management activities [28]. After using PRISM and, based on the assessments of the patient's fitness and his/her personal needs, the PT discusses with the patient how he/she can integrate more exercise into his/her everyday life. The fitness assessments help to identify the exercise dimension(s) with potential for improvement. In this regard, counselling may focus on raising consciousness, reinforcing the patients' PA behaviour, avoidance of relapse, or maintenance strategies. For example, some patients may need support in increasing the active time spent on light activities and reducing sedentary behaviour, while others may need a structured exercise plan to participate in a half-marathon. With each patient an individual goal and action plan is developed in a shared decision process.

Group counselling interventions may vary in time (5-45 min) and can be designed differently, according to the needs and interests of the group. Examples are, (a) theoretical and practical training on heart rate self-monitoring during aerobic exercise, and (b) group discussion on how to cope with barriers.

\section{d. Fitness assessments}

During a regular exercise group session, a team of one senior (researcher) and several junior assessors (PT students) performs the fitness assessments with each participant, described as tertiary outcomes in Table 2 and Additional file 2. After the physical assessments, each patient is instructed to fill out six questionnaires at home. Furthermore, an exercise diary is explained and highly recommended, enabling feedback and reporting. Within 1 week, the individual assessment results are sent to the supervising PT for exercise counselling. 


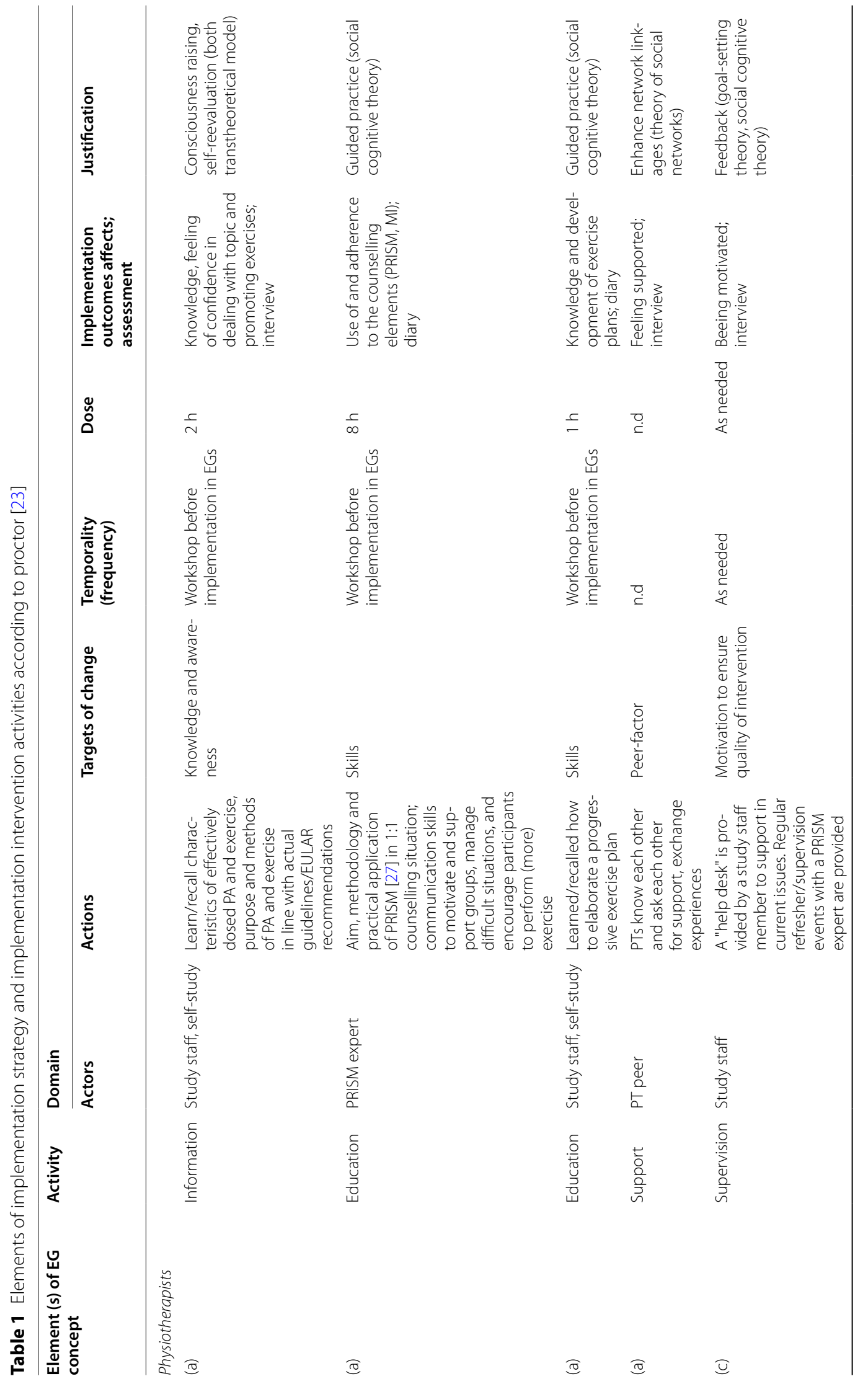




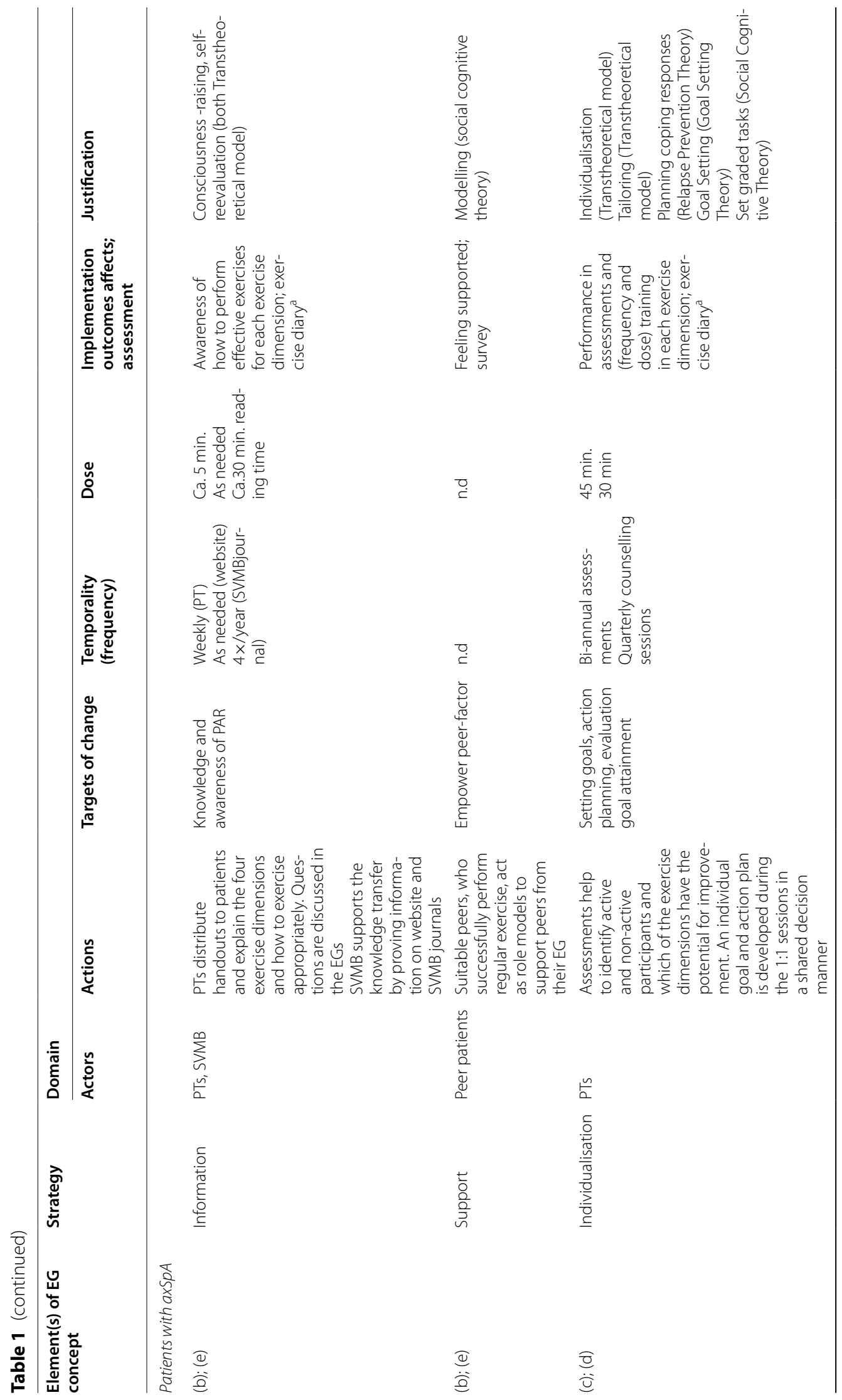




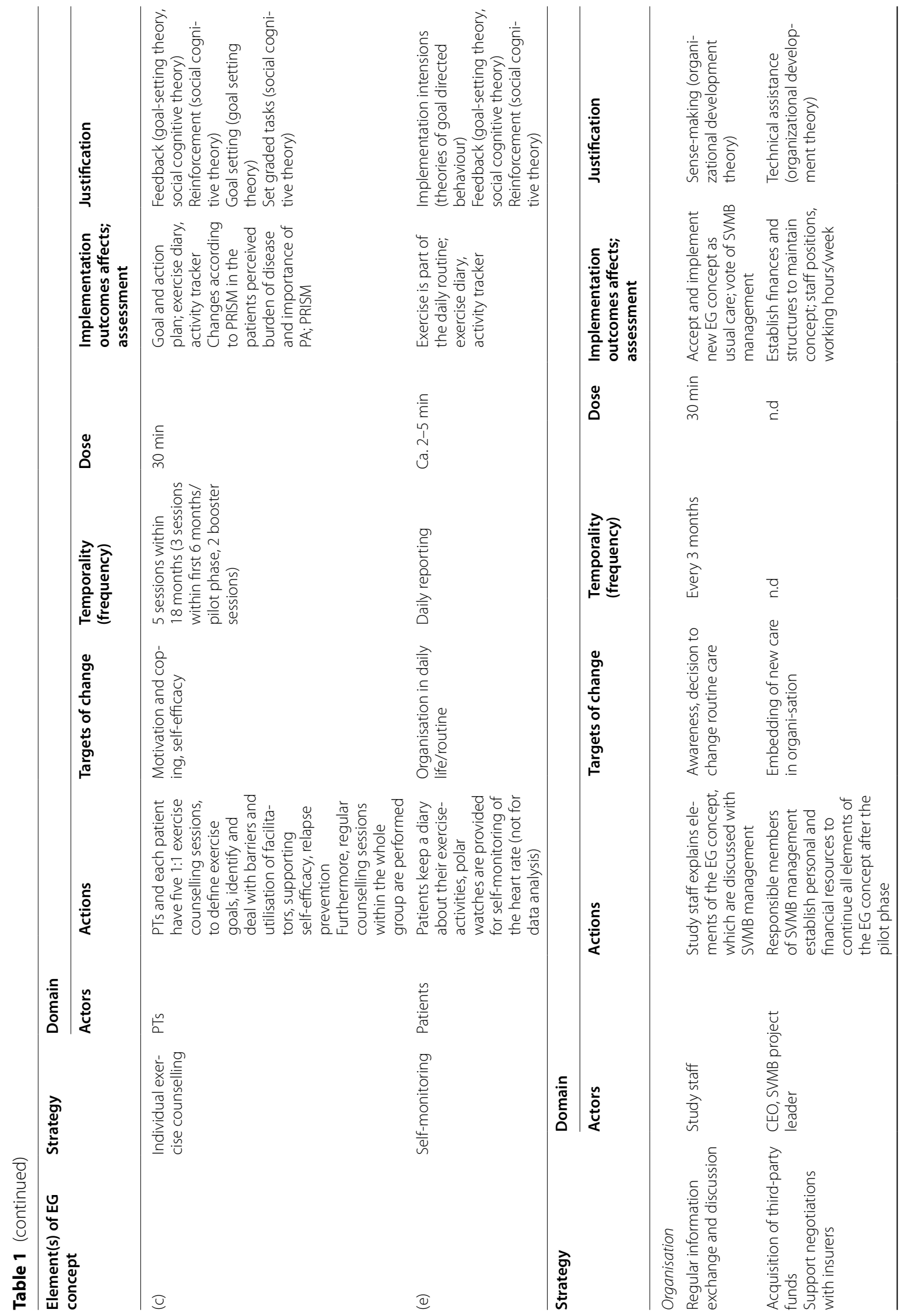




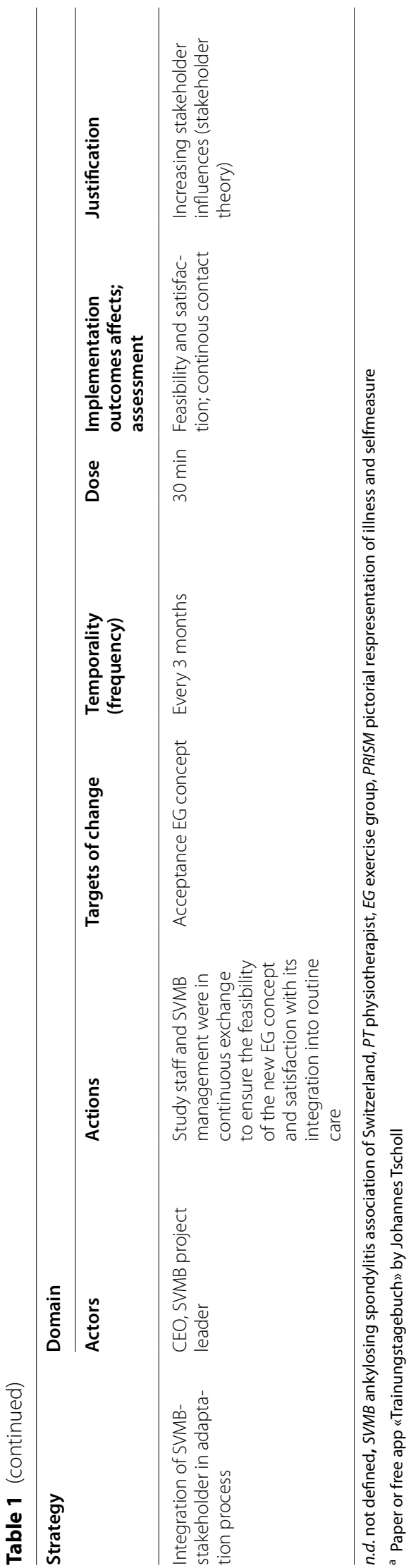




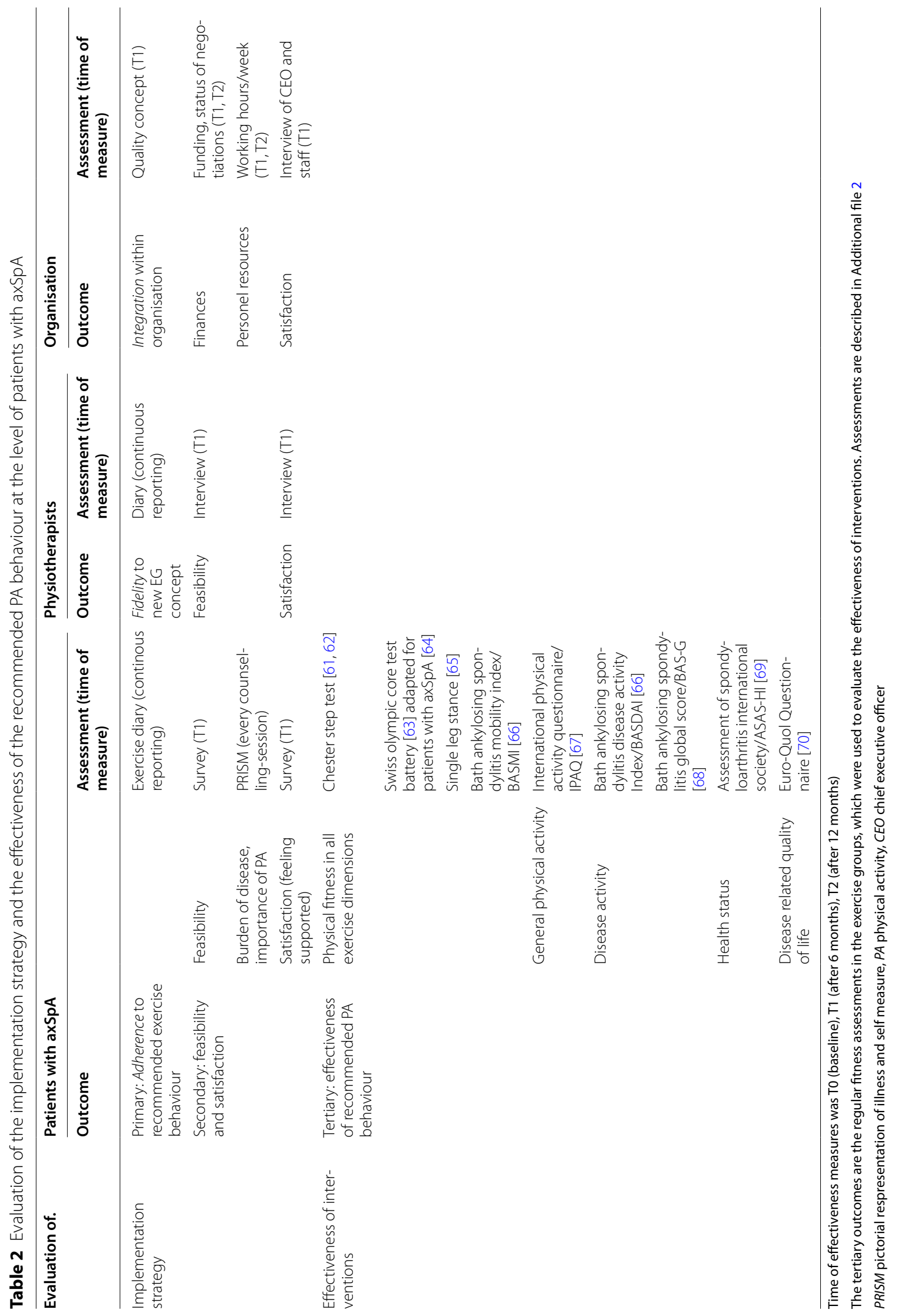




\section{e. Individual, unsupervised exercise training}

To fulfil the recommended amount of PA, one supervised exercise group a week is insufficient. The elements mentioned above should enable group members to engage in additional, unsupervised exercise. Based on the fitness assessments and personal preferences, the patient and PT agree on a training goal in one, or several, of the exercise dimensions and create an action plan. During the following counselling session, progress is evaluated and the goal reviewed.

Targeting the SVMB Regular meetings are held between SVMB management and study staff to ensure that the implementation activities align with the structures and processes of the SVMB. In addition, to increase the acceptance and feasibility of "moveSVMB", a significant effort is put into establishing a long-term financial strategy and personnel resources.

\section{Evaluations}

Evaluation at T1 The primary outcome for the evaluation at the patient level was adherence to the recommended exercise behaviour, assessed by the number of reported training sessions per exercise dimension in the electronic exercise diary for over 6 months. The secondary outcomes at $\mathrm{T} 1$ were feasibility and satisfaction with the new exercise group concept, rated on a $0-10$ numeric rating scale $(0=$ not satisfied, $10=$ very satisfied; if $>50 \%$ of patients rate $>5$, the concept was evaluated as "satisfying") and changes in the perceived burden of disease or importance of PA, measured with PRISM. The tertiary outcome to evaluate the effectiveness of the individualised PA recommendations was the measured changes in the fitness levels of patients (T0-T1), assessed by fitness parameters (Table 2).

The primary outcome for the evaluation atPT level was fidelity to the program design concept, assessed using a diary. Fidelity was rated as sufficient when $75 \%$ of PTs fulfilled the program. The secondary outcomes were treatment quality, feasibility and satisfaction, evaluated through semi-structured interviews.

The evaluation at the SVMB level focused on acceptance of the new exercise group concept and its establishment within organisational structures. In addition, regular progress meetings between study staff researchers and SVMB management were used to appraise the feasibility and effectiveness of the implementation interventions.

Evaluation at T2 Maintenance was monitored at T2 (1 year after T1) by assessing the number of patients and supervising PTs still adhering to the new group concept.

\section{Adaptations of "moveSVMB"}

After 6 months, the findings of evaluations on all three levels were considered while deciding on adaptations of the program concept of "moveSVMB". Both SVMB management and study staff agreed on findings that negatively impacted the feasibility. Accordingly, they developed adaptations needed for a successful nationwide implementation of the new exercise group concept.

\section{Study procedures}

The four pilot exercise groups, comprising the supervising PTs and 5-12 patients with axSpA, from the German-speaking region of Switzerland were asked by the SVMB management to volunteer. Criteria were a location close to the study center and the motivation and availability of PTs and group members. The partipicant PTs and patients were informed face-to-face about the new group concept "moveSVMB" well in advance. Group members decliningto be measured or not providing written informed consent were offered the usual exercise group intervention.

Eligibility criteria for patients with axSpA were $\geq 18$ years old, a member of a SVMB exercise group, and provision of written informed consent. All patients were screened for cardiovascular risk [29]. Patients identified as at increased risk required confirmation from a PT or medical doctor that a higher level of exercise was not contraindicated. Criteria for exclusion were medically relevant contradictions to exercise [8]. Eligibility criteria for PTs were being a superviser PT of an existing SVMB group, willingness to follow the implementation protocol of the new exercise group concept (including a 2 day educational workshop), and provision of written informed consent.

At the beginning of the pilot study, some organisational requirements were defined. A cooperation with the BSc in physiotherapy programme at the ZHAW was established to recruit second year PT students to perform the fitness assessments in exercise groups under the supervision of a senior researcher. Additionally, third-party funding was secured prior to the start of negotiations with insurers concerning reimbursement. Throughout the pilot phase, the SVMB provided personnel (project manager, c.a. $17 \mathrm{~h} /$ week (40\%), additional IT support), and was prepared to increase resources after evaluation of the pilot phase.

\section{Statistics}

Demographic, disease-specific, self-reported (diary or patient-reported outcome measures PROMS) and assessment data were presented as mean and standard deviations, or median and associated range for continuous 
data or as frequencies (percentages) for categorical variables. During the fitness tests, the maximal time of one leg stance was limited to $60 \mathrm{~s}$, this being the length of time indicating that the individual has no balance problem. For each exercise dimension, a linear mixed model with random intercept was fitted to the data with the withinsubject variables of time and measurement condition and the between-subject variables of age, disease duration, disease activity (Bath Ankylosing Spondylitis Mobility Index BASMI), and PA level (metabolic equivalent of tasks METs) as explanatory variables. PRISM data (in $\mathrm{cm})$ were correlated with the Bath Ankylosing Spondylitis Disease Activity Index (BASDAI) and weekly METs using spearman rank correlation. Paired t-tests and Wilcoxon tests, with corresponding parametric and nonparametric effect sizes (ES), were computed to analyse within-group changes. All statistical analyses were performed using the R statistical software, $\mathrm{R}$ version 3.5.2 ( $\mathrm{R}$ Foundation for Statistical Computing, Vienna, Austria).

\section{Results}

Demographic and clinical data of exercise group members Of the 43 patient members of the four pilot groups, 30 (70\%) signed informed consent and participated in the baseline assessments. Reasons for non-participation were reported by ten members of the groups: timing of assessments due to holidays (3), lack of time (2), age or disease activity (2), no interest (2), no axSpA (1). The characteristics of the four pilot groups are described in Table 3.

During the 6-month pilot phase, two patients dropped out due to specified reasons: "I do not need exercise counselling", and "it is too much pressure for me". In addition, two patients did not participate in the assessments after 6 months due to an influenza.

\section{Results at the level of patients with axSpA} Adherence to recommended exercise behaviour

Thirteen patients (43\%) submitted an exercise diary each week to assess adherence to PA recommendations. None of these thirteen people fulfilled the PA recommendations in all four exercise dimensions. Four patients fulfilled the recommended dose of weekly cardiovascular exercises, one the recommendation of one additional exercise dimension, and two patients the recommendations of two additional exercise dimensions.

\section{Feasibility and satisfaction}

The survey's response rate was $90 \%$ (27/30). Since two were returned empty, 25 were used for analysis. Of these, $15(62 \%)$ patients were satisfied with the concept "moveSVMB" (mean satisfaction $6.7 \pm 2.2$ ) and 20 (80\%) with the exercise counselling (mean satisfaction $7.7 \pm 2.9$ ). Patients rated and commented the use of PRISM contrary (11 "not useful" vs. 12 "useful"); appreciating ("I understand the relation between axSpA and my life" (ID15)) or criticising ("this is coffee cup reading to me" (ID05)).

Twenty-two (88\%) patients defined a training goal, 17 (68\%) developed an action plan and 15 (60\%) achieved their training goal. Sixteen (64\%) patients used the exercise diary, five used app-based reporting. Reasons for non reporting were: the daily effort, technical problems with the app, and problems with allocating activities to exercise dimensions correctly (e.g. is the SVMB exercise group strength or neuromotor exercising?). Personal adaptations were made to individual exercise goals (e.g. in terms of frequency or intensity of training) and to individual exercise diaries (e.g. notes in the personal agenda instead of the proposed sheets). A minority $(\mathrm{n}=7,28 \%)$ reported using a technical device (such as a

Table 3 Characteristics of axSpA patients and supervising PTs at baseline

\begin{tabular}{|c|c|c|c|c|c|}
\hline Characteristics & Total & Group 1 & Group 2 & Group 3 & Group 4 \\
\hline \multicolumn{6}{|l|}{ Patients with axSpA } \\
\hline Total number per group (n) & 43 & 8 & 11 & 8 & 16 \\
\hline Number participating in "moveSVMB" (n) & 30 & 3 & 6 & 7 & 14 \\
\hline Gender, women, n (\%) & $10(33.3)$ & $1(33.3)$ & $2(33.3)$ & $2(28.5)$ & $5(35.7)$ \\
\hline Years of age (median, range) & $57.5(37-75)$ & $68(37-72)$ & $58(51-71)$ & $57(45-68)$ & $56.5(49-75)$ \\
\hline Disease duration, years (median, range) & $30(12-60)$ & $49(23-51)$ & $33(20-46)$ & $30(18-35)$ & $30(12-60)$ \\
\hline ASAS-HI (median, range) & $2.1(0-11)$ & $1(0-3)$ & $2.1(0-6)$ & $2(0-8)$ & $3(0-11)$ \\
\hline $\begin{array}{l}\text { Physical activity level (IPAQ), total MET per } \\
\text { week (median, range) }\end{array}$ & $3919(1520-14,958)$ & $3916(2526-6933)$ & $5820(2298-10,260)$ & $2697(1600-10,638)$ & $2853(1520-14,958)$ \\
\hline \multicolumn{6}{|l|}{ Supervising PTs $(n=4)$} \\
\hline PT group leader, gender (female/male) & - & f & $f$ & $f$ & $\mathrm{~m}$ \\
\hline PT group leader, age, years (median, range) & $48.2(34-54)$ & 52 & 45 & 34 & 54 \\
\hline PT group leader since, years (median, range) & $12(2-23)$ & 23 & 8 & 2 & 16 \\
\hline
\end{tabular}

$n$ number, $A S A S-H I$ assessment of spondyloarthritis international society health index, $P T$ physiotherapists, IPAQ international physical activity questionnaire 
heart rate tracker) for cardiovascular exercise. Seventeen $(68 \%)$ were satisfied with the fitness assessment (mean $7.5 \pm 1.8$ ). Patients did not use the project name "moveSVMB" but suggested names such as "Bechterew-Fit" or "Bechterew-Gymnastics".

\section{Changes according to PRISM}

Neither the perceived burden of disease (distance to self at T0: $13.7 \pm 7.2 \mathrm{~cm}$; at T1: $12.1 \pm 6.2 \mathrm{~cm} ; \mathrm{t}=0.386$, $p=0.703$ ) nor the importance of PA (distance to self at, T0: $7.3 \pm 5.3 \mathrm{~cm}$; at T1: $7.0 \pm 4.5 \mathrm{~cm}) ; \mathrm{t}=0.246, p=0.808$ ) changed over 6 months. The perceived importance of PA correlated with the International Physical Activity Questionnaire (IPAQ) measured METs at $\mathrm{T} 1(\mathrm{r}=0.572$, $p=0.00$ ), no correlation between perceived burden of disease and METs was found.

\section{Effectiveness of individualised PA recommendations: fitness status}

Table 4 reports the results of the fitness assessments at baseline (T0) and after 6 months (T1). Patients' cardiorespiratory fitness [ES 1.22 (95\%CI 0.59, 1.90), large ES and significant] and core strength ventral muscle chain [ES 0.62 (95\%CI 0.19, 1.06), medium ES and significant] improved over the 6 months. Core strength lateral and dorsal muscle chain, balance and flexibility did not change significantly over 6 months.

The linear mixed model analysis showed that disease activity was negatively (slope $=-1.49, p=0.01$ ) associated with cardiorespiratory fitness and the PA level $(\mathrm{MET})$ positively $($ slope $=3.28, p=0.01)$. The PA level was also positively associated with core muscle strength (slope $=8.62, p=0.05)$. Age was positively associated with flexibility (slope $=0.10, p=0.04$ ), but negatively associated with balance time (slope $=-0.84(p=0.00)$.

\section{Results at the PT level}

\section{Fidelity to the new exercise group concept}

Three of the four PTs (75\%) performed and reported on three group counselling sessions within the 6 months, with a mean duration of $18( \pm 13)$ minutes. Due to a misunderstanding, one PT did no group counselling sessions. The counselling sessions consisted of knowledge transfer (e.g. reading and discussing PA recommendations) and skills training (e.g. training with a heat rate monitor). The number of patients participating in the group counselling interventions varied between four and twelve per session and group.

All four PTs performed and reported three individual exercise counselling sessions with 27 of 30 patients (90\%). Two patients dropped out after the first session andne patient participated in only two sessions before leaving the group for personal reasons. Of the 27 patients receiving the three counselling sessions, 11 (40\%) received the three counselling sessions within 6 months, as required by the concept; 10 (37\%) within 9 months, and six (22\%) within 12 months. The delay was due to organisational factors in all cases.

The mean duration of an individual counselling session was $35( \pm 7)$ minutes. During the first session, the PTs used the PRISM to take the patient's history, explain the results of the fitness assessment and, through shared decision-making, to define one, or more, training goals. Subsequently, based on the patient's preferences, an action plan was developed. During the second and third sessions, PTs used PRISM to evaluate, together with the patient, whether the goal(s) had been reached, or whether adaptations to the goals or planned actions were needed due to changes in fitness status or PA-behaviour.

The mean duration of PRISM usage was $9( \pm 3)$ minutes during the first session, $10( \pm 4)$ minutes during the second, and $7( \pm 3)$ minutes during the third.

Using PRISM, PTs measured and reported on the burden of disease and importance of PA for 25 participants.

\section{Feasibility and satisfaction}

PTs perceived the PRISM communication and exercise counselling as very useful, since they previously had little knowledge of the history and exercise goals of their patients. Exercise counselling supported the possibility of personalized exercise. They emphasised that the frequency of the sessions must be flexibly planned, based on the patient's individual training goal and motivation. The PRISM was perceived as a useful door opener, triggering emotions and information, if the patient's attitude was open to the new communication tool. PTs reported that they initially felt unconfident when applying PRISM; this feeling was diminished during the pilot phase through supervision and practice. The PTs perceived varyingreactions from patients regarding the fitness assessments, some found that they increased motivation to exercise and others found them demotivating. During exercise counselling, PTs indicated that they found the fitness assessment data difficult to interprete because of the lack of background information (e.g. norm data) and that they rarely relied on them. The PTs felt, that the frequency of fitness assessments could be reduced from bi-annually to annually.

\section{Results at the organisational level}

Satisfaction and commitment of the SVMB management was found to be high after the pilot phase. Consequently, the SVMB management decided to integrate the new exercise group concept into the organisation and implement it as the new usual care in all its SVMB exercise groups. 
Table 4 Results of fitness assessments of the whole patient sample at T0 (baseline) and T1 (after 6 months)

\begin{tabular}{|c|c|c|c|c|}
\hline $\begin{array}{l}\text { Fitness assessment } \\
\mathrm{n} \text { missing values } \\
\text { mean (SD) } \\
\text { median (IQR 25/75) }\end{array}$ & $\begin{array}{l}\text { T0 } \\
(\mathrm{n}=30)\end{array}$ & $\begin{array}{l}\mathrm{T} 1 \\
(\mathrm{n}=30)\end{array}$ & Change $(n=30)$ & $\begin{array}{l}\text { ES } \\
\text { (95\% confidence interval) }\end{array}$ \\
\hline Cardiorespiratory fitness, VO2max & & & & $* 1.22(0.59,1.90)$ \\
\hline $\mathrm{n}$ missing values & 4 & 11 & 13 & \\
\hline mean (SD) & $35.2(6.5)$ & $41.6(6.5)$ & $7.9(6.5)$ & \\
\hline median (IQR 25/75) & $34.5(32.6 / 39.7)$ & $39.9(38.2-46.0)$ & & \\
\hline Corestrength, ventral, sec & & & & ${ }^{*} 0.62(0.19,1.06)$ \\
\hline $\mathrm{n}$ missing values & 1 & 5 & 5 & \\
\hline mean (SD) & $78.8(51.9)$ & $107.5(65.4)$ & $23.8(38.6)$ & \\
\hline median (IQR 25/75) & $69.0(40.0-100.0)$ & $90.0(64.0-149.0)$ & & \\
\hline Core strength, lateral, sec & & & & $0.17(0.01,0.55)$ \\
\hline $\mathrm{n}$ missing values & 1 & 5 & 5 & \\
\hline mean (SD) & $49.0(31.5)$ & $57.9(31.1)$ & $7.6(30.2)$ & \\
\hline median (IQR 25/75) & $39.0(29.0-66.0)$ & $51.0(38.0-82.0)$ & & \\
\hline Core strength, dorsal, sec & & & & $0.30(0.02,0.65)$ \\
\hline $\mathrm{n}$ missing values & 1 & 7 & 7 & \\
\hline mean (SD) & $58.5(50.1)$ & $71.7(56.6)$ & $9.7(35.5)$ & \\
\hline median (IQR 25/75) & $35.0(24.0-80.0)$ & $59.0(32.5-85.5)$ & & \\
\hline Oneleg stance, open eyes, mean of 3 reps, sec & & & & $0.10(0.00,0.48)$ \\
\hline $\mathrm{n}$ missing values & 0 & 4 & 4 & \\
\hline mean (SD) & $43.1(21.1)$ & $46.6(19.6)$ & $3.7(14.0)$ & \\
\hline median (IQR 25/75) & $60.0(24.5-60.0)$ & $60.0(34.0-60.0)$ & & \\
\hline One leg stance, closed eyes, mean of 3 reps, sec & & & & $0.30(0.02,0.63)$ \\
\hline $\mathrm{n}$ missing values & 0 & 4 & 4 & \\
\hline mean (SD) & $7.7(5.8)$ & $9.5(7.8)$ & $1.7(5.5)$ & \\
\hline median (IQR 25/75) & $5.5(5.0-15.5)$ & $7.9(3.0-14.9)$ & & \\
\hline BASMI, Score & & & & * $-0.28(-0.68,0.12)$ \\
\hline$n$ missing values & 0 & 4 & 4 & \\
\hline mean (SD) & $3.1(2.3)$ & $2.9(2.0)$ & $-0.2(0.9)$ & \\
\hline median (IQR 25/75) & $2.4(1.2-4.5)$ & $2.3(1.2-4.7)$ & & \\
\hline IPAQ, MET perweek & & & & $0.15(0.00,0.58)$ \\
\hline $\mathrm{n}$ missing values & 1 & 9 & 10 & \\
\hline mean (SD) & $5013(3479)$ & $4101(4262)$ & $-199.8(2712.2)$ & \\
\hline median (IQR 25/75) & $3916(1520-14,958)$ & $3150(1470-4502)$ & & \\
\hline BASDAl & & & & ${ }^{*} 0.06(-0.39,0.51)$ \\
\hline $\mathrm{n}$ missing values & 1 & 9 & 10 & \\
\hline mean (SD) & $3.0(1.7)$ & $3.0(2.2)$ & $0.0(1.1)$ & \\
\hline median (IQR 25/75) & $3.0(1.8-4.1)$ & $2.2(1.3-4.4)$ & & \\
\hline BAS-G & & & & $0.02(0.00,0.49)$ \\
\hline $\mathrm{n}$ missing values & 1 & 9 & 10 & \\
\hline mean (SD) & $2.9(1.8)$ & $2.6(1.8)$ & $-0.2(1.6)$ & \\
\hline median (IQR 25/75) & $2.4(1.4-4.5)$ & $2.2(1.1-3.7)$ & & \\
\hline ASAS-HI & & & & $0.12(0.00,0.54)$ \\
\hline $\mathrm{n}$ missing values & 1 & 9 & 10 & \\
\hline mean (SD) & $3.0(2.6)$ & $2.5(0.7)$ & $-0.8(3.3)$ & \\
\hline median (IQR 25/75) & $2.1(1.0-4.0)$ & $3.0(2.0-3.0)$ & & \\
\hline
\end{tabular}

Effect sizes (ES) were computed from Wilcoxon tests and paired t-tests, using $r$ for non-parametric and cohen's $d$ for parametric* analysis, respectively. Interpretation of ES: r: $0.1-0.3$ (small), $0.3-0.5$ (moderate) and >0.5 (large). Cohen's d: 0.2 (small), 0.5 (medium), 0.8 (large)

IQR interquartilrange, sec seconds, SD standard deviation, BASMI bath ankylosing spondylitis mobility index, reps repetitions, IPAQ international physical activity questionnaire, BASDA/ bath ankylosing spondylitis disease activity index, BAS-G bath ankylosing spondylitis patient global score, ASAS-HI assessment of spondyloarthritis international society health index 


\section{Maintenance}

After 1 year (T2), the same supervising PTs were responsible for their exercise groups and were actively involved in the nationwide implementation process. The four pilot exercise groups lost one member due to personal reasons, but gained two newmembers. Therefore, 29 patients actively participated in the programme, of whom 21 (72\%) participated in the fitness assessments at $\mathrm{T} 2$.

\section{Adaptations to the implementation strategy}

Some implementation activities were found to be not fully feasible in our setting. Minor adaptations were made to improve adherence to the recommended exercise behaviour (patients), concept fidelity (PTs), and feasibility ofnationwide implementation (SVMB). The barriers and adaptations are described in Table 5.

Exercise counselling and the fitness assessments were generally appreciated by the patients, but the frequencies of both was perceived as being too high. Accordingly, the fitness assessments were reduced from bi-annually to annually, and the individual exercise counselling sessions reduced from three to two sessions in the first 6 months. The first session was compulsory for all participants and the second dependent on individual needs and training goals. The group counselling sessions were perceived to be useful, but the definition of frequency and structure was removed. There is a great need for a simple exercise diary, covering all the exercise dimensions. An improvement was made to the paper diary through providing better explanations. This version will be used until a digital exercise diary becomes available.

The 2 day educational workshop for PTs was thought to be too time-consuming for clinicians. Furthermore, the information strategy of the SVMB had already increased awareness and knowledge ofthe new concept amongst thePT community. The training will therefore be reduced to 1 day and the workshop will focus on exercise counselling (including behavioural change techniques and PRISM).

Based on suggestions from patients, the name "moveSVMB" was changed by the SVMB to BeFit ("Bechterew Fitness") and a new logo was developed. Following the pilot phase, information about BeFit was released by the SVMB, with no involvement of the study staff. In addition, the financial and personnel resources were established to ensure a continuation of the implementation.

\section{Discussion}

To our knowledge, this is the first study to translate and implement PA recommendations within a specific patient organisation into an exercise group concept for patients with axSpA and their supervising PTs. Findings will inform the nationwide implementation in Switzerland and similar projects in the Netherlands.

The findings of the pilot phase found the implementation strategy was acceptable and satisfactory to patients, PTs, and the SVMB. This resulted in SVMB management adopting the exercise group concept as its new usual care and implementing it in all its exercise groups. Successful implementation can only happen if the SVMB takes responsibility and initiates crucial changes at organisational level. Findings generally confirm the value of evidence-based exercise groups provided by a patient organisation to support active PA behaviour.

The patients' adherence to recommended exercise behaviour was assessed as insufficient. Reasons for nonadherence of patients may be two-fold: (1) The assessment of adherence to recommended exercise behaviour in patients with axSpA was difficult due to technical problems with the app and possible reporting bias; (2) the adherence was low in terms of performing insufficient amount of exercise according to recommended frequency and dose, as well as reporting exercise sessions. According to the reporting, only four patients fulfilled the recommended amount of aerobic exercise, three of them fulfilled one or two additional exercise dimensions. Factors like limited personal motivation may moderate the level of adherence to change current exercise behaviour or difficulty to achieve the agreed goals. However, it would have been useful to have learned more about the attitude of the patients towards changing their PA behaviour through asking them, prior to the first counselling session, about their satisfaction with their current PA level and whether they were motivated to increase their exercise behaviour. To show improved fitness in exercise dimensions, specific and adequately dosed training is needed. The implementation fidelity in PTs was found to be good, with their adherence to performance and the reporting of exercise counselling beeing sufficient. The level of adherence was affected by factors such as patient' responsiveness, quality of counselling, and organisational aspects (e.g. time constraints). However, only small organisational adaptations needed to be made by the PTs, according to the individual local group setting, such as to the scheduling and the setting of counselling sessions. The reduced number and more flexible planning 
Rausch Osthoff et al. BMC Rheumatology

(2022) 6:12

Page 14 of 18

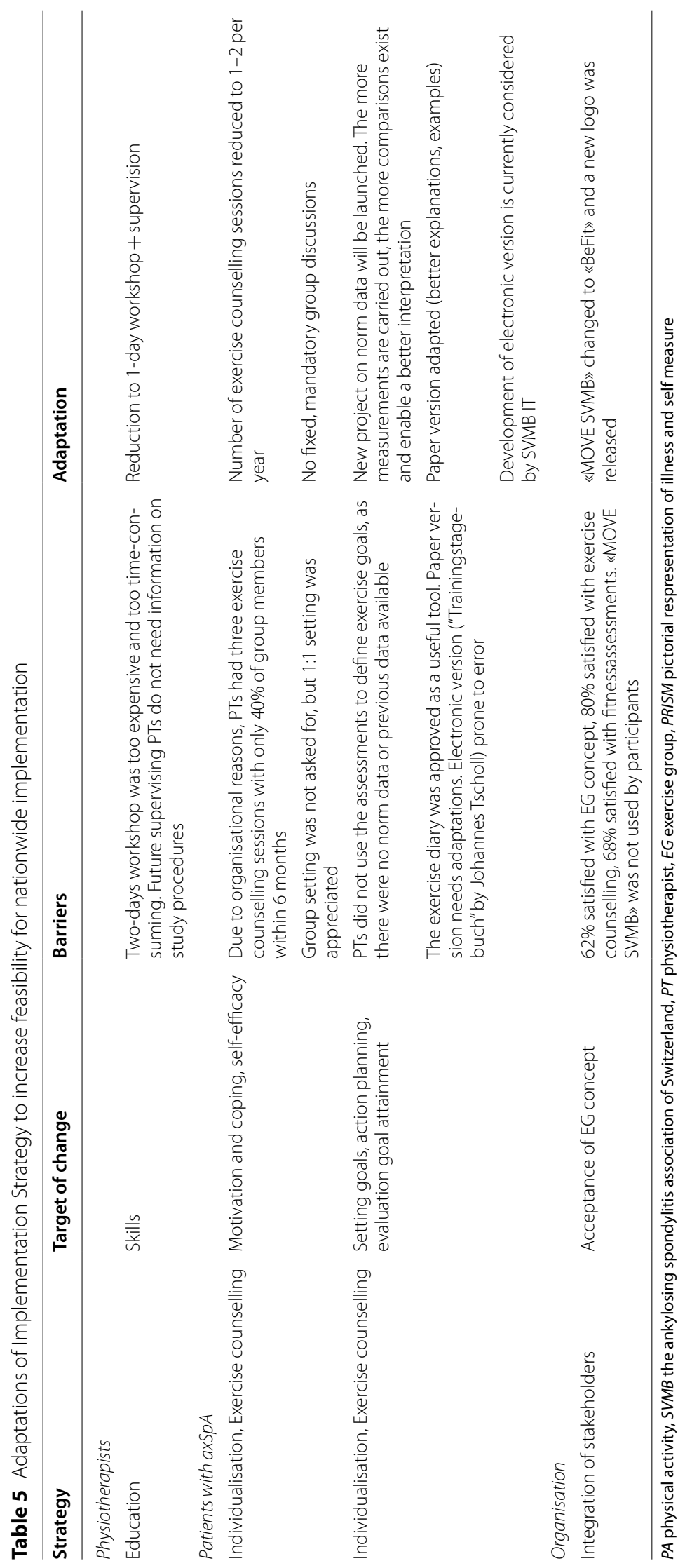


of counselling sessions should enhance feasibility in the future and result in improved performance (during pilot study only $40 \%$ of patients had the counselling sessions within 6 months).

The four pilot PTs could be viewed as a special group since they were presumably "innovators", an active group keen on new ideas and innovations [30,31]. The pilot PTs were immediately willing to adapt their usual care and confirmed the value of change. Grol and Wensing describe five phases in the process of change for health professionals: orientation, insight, acceptance, change, maintenance [19]. Other supervising PTs might be harder to persuade of the benefits of the new concepts, since old routines need to be first de-implemented to move from acceptance to change and maintenance. Therefore, clear leadership by the SVMB management and the pilot PTs, as role models, are essential for the further implementation among supervising PTs.

Patients reporting could be improved in future though technical applications, which might be more appropriate to the collection of objective data than a paper diary [32]. These could also be used as a promotion strategy (e.g. feedback, reinforcement) [33, 34]. However, the assessment of PA and reporting on all fitness dimensions simultaneously in the same tool is a big challenge, and a perfect tool is not yet available [35, 36]. The adapted paper version of the diary must serve as a placeholder until an electronic solution is developed.

PT needs two critical competencies to work with an exercise group: detailed knowledge of the PA recommendations and communication skills. Even though PA promotion is a key concept of physical therapy [37], and both patients and PTs agree that advice and support of active PA behaviour is part of the therapist's role $[38,39]$, there seems to be a PT educational gap. Data from the UK and Canada indicate that the majority of PTs neither have detailed knowledge of PA recommendations, nor meet the recommended PA level themselves [40, 41].

A preliminary analysis of counselling sessions has revealed that during the first counselling session one of the techniques most used by PTs to change behaviour [42] was 'general intention building'. No specific goal setting technique was applied (unpublished data). PTs generally use only a few behavioural change techniques [43]. This finding underpins the need for continuous training of PTs in communication and behaviour change techniques. Hilberdink and colleagues [44] have mapped a toolkit to optimise exercise behaviour of people with axSpA: (1) Patients should be offered behavioural change guidance, including education, motivational interviewing, goal setting, action planning, monitoring and feedback. Patients need to be encouraged to exercise in a group setting. (2) PTs need to be educated to tailor and instruct an exercise program and apply behaviour change techniques. Some first effort is made to downscale the lack of evidence-based education and training for health professionals working with rheumatic conditions [45]. Others $[9,44,46]$ emphasise that interventions are needed for patients with axSpA including behaviour change techniques, that aim to deliver intrinsic motivation to overcome barriers to exercise [47-49] and to sustain an active lifestyle.

In this project, it took several years to determine the appropriate implementation process, following the cyclical approach of Grol and Wensing's implementation of change model [19]. During this development period Koorts and colleagues [47] published the PRACTIS guide, which supports the planning and scaling-up of physical activity implementation projects. PRACTIS focuses more specifically on PA promotion research translation and gives detailed "how to" support. Both approaches have a common ground and are appropriate theoretical approaches to describe an implementation process and to explain what influences implementation outcomes and the implementation success. One strength of this pilot project is that an implementation scientist was involved from the start, following the "innovative collaborative model" [48]. Further strengths are the indepth contextual analysis that has been undertaken [20, $21]$ and the stakeholder involvement from the beginning.

The group setting for exercise therapy is considered equally effective as individual therapy, but with lower healthcare cost [49]. Furthermore, group therapy is attributed a potentially motivating factor for physical activity behaviour change [50]. Despite this knowledge, however, the social rules or "group dynamics" [51] within the pilot groups and their impact on individual motivation or PA adherence was not investigated in this study. Social learning [52] within group activities (counselling, and assessment) appears to be an important subject and should be investigated further in future studies.

The sample size of the four pilot groups with 30 patients was small. However, since effectiveness aspects were not the main focus, no prior sample size calculation or bias-prevention, such as blinding, were necessary. According to literature, men and women are equally affected by axSpA [53]. However, in the pilot groups there were more men than women participated (2:1 ratio). A further limiting factor is the use of selfreported outcomes and not of validated assessments to measure the implementation success. However, this approach was pragmatic and feasible. Future research projects should try to overcome these limitations. The exercise group concept could be a valuable strategy in enhancing patients' daily exercise routines. However, fulfilling the PA recommendations in all exercise 
dimensions is a very high goal. Continuous monitoring of the exercise group concept is needed to follow-up on patients' exercise behaviour and further improve the strategies of how to fulfil the PA recommendations.

Many patients prefer individual therapy. For example, $32 \%$ of the Swiss axSpA patients prefer individual, mainly inactive therapy [20]. Dutch patients participating in axSpA exercise groups, however, were positive about subsequently established additional home exercises, annual assessments and training using heart-rate monitors [54]. To reach patients who prefer an individual setting, or the inactive therapy approach, a patient education and PA promotion concept supporting the understanding of exercise as medicine needs to be developed.

Further research is also needed to investigate the effects on patients with axSpA of strength or neuromotor exercises alone, not in combination with cardio-respiratory exercises, since no such studies have been conducted as yet [11]. It has also previously been stated that flexibility exercises are beneficial to spinal flexibility [2]. However, no studies on flexibility exercises alone were found althoughexercises combined with muscle strength or aerobic exercise did not affect flexibility [11]. Recent studies have confirmed that intensive cardio-respiratory exercise is effective, safe and feasible in patients with axSpA [55]. No detrimental effects were shown, rather a beneficial impact on disease activity and risk of cardiovascular diseases was approved $[9,56,57]$. Similar strong evidence is lacking for the other fitness dimensions. A recently published review confirmed that exercise intervention studies in people with inflammatory arthritis are not adequately reported, neither was the exercise dose underpinned with evidence [58]. Furthermore, better knowledge of adherence patterns, e.g. coping mechanism related to $\mathrm{PA}$, or patient profiles matching group versus individual exercise modes, is needed [59].

During a national implementation, continuous monitoring will be needed to avoid ineffective elements of the exercise group concept [60]. The balance between fidelity (degree of adherence) to and adaptation of the implementation strategy and interventions (the degree to which users modify the strategy and interventions to suit local needs) should be monitored and evaluated. A threshold for patient adherence should be defined for better evaluation of an implementation success. Furthermore, economic analysis on the levels of patient, provider, organisation and system should be performed to evaluate the concept's efficacy from an economical point of view.

\section{Conclusions}

This manuscript describes an implementation strategy to translate PA recommendations for patients with axSpA into a new exercise group concept for clinical practice and to embed then into the routine process (usual care) of a patient organisation. The implementation strategy was successfully evaluated in a pilot study including key stakeholders: patients, PTs, and patient organisation. The implementation project addressed a need at organisational level through delivering evidence-based therapy to patients and enhancing the competencies of the supervising PTs. Based on the results of the pilot study, technical problems, which hampered a reliable evaluation of the adherence rate of patients, and some other adaptations were necessary to increase the feasibility for a nationwide implementation. Further work is required in order to improve the quality of the assessments, the exercise counselling, and the individual exercising. The successful pilot strategy and necessary adaptations are explained in detail to make the knowledge available to future translational research projects in the field of RMDs. The upcoming nationwide implementation process needs to be monitored so that implementation problems or changes in the needs of patients with axSpA, PTs, or SVMB can be addressed early.

\section{Supplementary Information}

The online version contains supplementary material available at https://doi. org/10.1186/s41927-021-00233-z.

Additional file 1. Standards for Reporting Implementation Studies: the StaRI checklist for completion.

Additional file 2. Description of assessments (PRISM, fitness assessments, interview with PTs).

\section{Acknowledgements}

We thank all individuals with axSpA and physiotherapists who participated in the project. Furthermore, we are grateful to René Braem, CEO of the Swiss Ankylosing Spondylitis Association, for supporting the project. Many thanks also go to Christian Horvath and Chiara Scherrer for their help during data collection.

\section{Authors' contributions}

AKRO drafted the manuscript, all authors reviewed it for important intellectual content, all authors approved the final version to be published. Study initialisation and execution: AKRO, KN. Study conception and design: AKRO, KN, TV, LVB, SB, AC. Acquisition of data: AKRO, KN, BT, IN. Analysis and interpretation of data: AKRO, KN, IN, AM, TVV, LVB. All authors read and approved the final manuscript.

\section{Funding}

The project was supported financially by Kurt-and-Senta-Herrmann-Foundation (Vaduz) and Zurich rheumatology foundation (Zurich).

Availability of data and materials

Please contact authors for data requests. 


\section{Declarations}

\section{Ethics approval and consent to participate}

The regional ethics committee (EC,Canton Zurich) approved the study on $30^{\text {th }}$ May 2018 (BASEC-Nr. 2018-00145). Data collection was conducted in accordance with Good Clinical Practice protocols and the Declaration of Helsinki principles. All participants (PTs and patients) received written and oral information about the study. Written informed consent was obtained from all participants prior to baseline measurement.

\section{Consent for publication}

Not applicable.

\section{Competing interests}

The authors declare no competing interests.

\section{Author details}

'ZHAW, School of Health Sciences, Institute of Physiotherapy, Zurich University of Applied Sciences, Katharina-Sulzer-Platz 9, 8401 Winterthur, Switzerland. ${ }^{2}$ Department of Orthopaedics, Rehabilitation and Physical Therapy, Leiden University Medical Center, Leiden, The Netherlands. ${ }^{3}$ Department of Biomedical Data Sciences, Leiden University Medical Center, Leiden, The Netherlands. ${ }^{4}$ Swiss Ankylosing Spondylitis Association, Zurich, Switzerland. ${ }^{5}$ Clinic for Psychotherapy and Psychosomatics Hohenegg, Meilen, Switzerland. ${ }^{6}$ Department of Rheumatology, Zurich University Hospital, 8091 Zurich, Switzerland.

Received: 21 May 2021 Accepted: 5 October 2021

Published online: 17 January 2022

\section{References}

1. Mathieu S, Gossec L, Dougados M, Soubrier M. Cardiovascular profile in ankylosing spondylitis: a systematic review and meta-analysis. Arthritis Care Res (Hoboken). 2011;63(4):557-63.

2. Dagfinrud H, Kvien TK, Hagen KB. Physiotherapy interventions for ankylosing spondylitis. Cochrane Database Syst Rev. 2008;2009(1):CD002822.

3. Dursun N, Sarkaya S, Ozdolap S, Dursun E, Zateri C, Altan L, et al. Risk of falls in patients with ankylosing spondylitis. J Clin Rheumatol. 2015;21(2):76-80

4. Sahin N, Ozcan E, Baskent A, Karan A, Kasikcioglu E. Muscular kinetics and fatigue evaluation of knee using by isokinetic dynamometer in patients with ankylosing spondylitis. Acta Reumatol Port. 2011;36(3):252-9.

5. Peters MJ, Visman I, Nielen MM, Van Dillen N, Verheij RA, van der HorstBruinsma IE, et al. Ankylosing spondylitis: A risk factor for myocardial infarction? Ann Rheum Dis. 2010;69(3):579-81.

6. van der Heijde D, Ramiro S, Landewe R, Baraliakos X, Van den Bosch F, Sepriano A, et al. 2016 update of the ASAS-EULAR management recommendations for axial spondyloarthritis. Ann Rheum Dis. 2017:76(6):978-91.

7. Noureldin B, Barkham N. The current standard of care and the unmet needs for axial spondyloarthritis. Rheumatology (Oxford). 2018;57(suppl_6):vi10-7.

8. Rausch Osthoff AK, Niedermann K, Braun J, Adams J, Brodin N, Dagfinrud $H$, et al. 2018 EULAR recommendations for physical activity in people with inflammatory arthritis and osteoarthritis. Ann Rheum Dis. 2018;77(9):1251-60

9. Sveaas SH, Bilberg A, Berg IJ, Provan SA, Rollefstad S, Semb AG, et al. High intensity exercise for 3 months reduces disease activity in axial spondyloarthritis (axSpA): a multicentre randomised trial of 100 patients. $\mathrm{Br} J$ Sports Med. 2019:54:292-7.

10. Peter WF, Swart NM, Meerhoff GA, Vliet Vlieland TPM. Clinical practice guideline for physical therapist management of people with rheumatoid arthritis. Phys Ther. 2021. https://doi.org/10.1093/ptj/pzab127.

11. Rausch Osthoff AK, Juhl CB, Knittle K, Dagfinrud H, Hurkmans E, Braun J, et al. Effects of exercise and physical activity promotion: meta-analysis informing the 2018 EULAR recommendations for physical activity in people with rheumatoid arthritis, spondyloarthritis and hip/knee osteoarthritis. RMD Open. 2018;4(2):e000713.
12. Garber CE, Blissmer B, Deschenes MR, Franklin BA, Lamonte MJ, Lee IM, American College of Sports Medicine position stand, et al. Quantity and quality of exercise for developing and maintaining cardiorespiratory, musculoskeletal, and neuromotor fitness in apparently healthy adults: guidance for prescribing exercise. Med Sci Sports Exerc. 2011;43(7):1334-59.

13. American College of Sports M. ACSM's guidelines for exercise testing and prescription. 10th ed. Philadelphia: Wolters Kluwer; 2018.

14. Ferreira de Meneses S, Rannou F, Hunter DJ. Osteoarthritis guidelines: barriers to implementation and solutions. Ann Phys Rehabil Med. 2016;59(3):170-3.

15. Swinkels RAHM, van Peppen RPS, Wittink H, Custers JWH, Beurskens AJHM. Current use and barriers and facilitators for implementation of standardised measures in physical therapy in the Netherlands. BMC Musculoskelet Disord. 2011. https://doi.org/10.1186/1471-2474-12-106.

16. McGuire WJ. Attitudes and attitude change. In: Lindzey G, Aronson E, editors. Handbook of social psychology: special fields and applications, vol. 2. 3rd ed. New York: Random House: 1985. p. 233-346.

17. Nicolson PJA, Hinman RS, French SD, Lonsdale C, Bennell KL. Improving adherence to exercise: Do people with knee osteoarthritis and physical therapists agree on the behavioral approaches likely to succeed? Arthritis Care Res (Hoboken). 2018;70(3):388-97.

18. Roter DL, Hall JA, Merisca R, Nordstrom B, Cretin D, Svarstad B. Effectiveness of interventions to improve patient compliance: a meta-analysis. Med Care. 1998;36(8):1138-61.

19. Grol R, Wensing M, Eccles M, Davis D. Improving patient care. The implementation of change in health care. 2nd ed. Oxford: Wiley Blackwell; 2013.

20. Rausch Osthoff AK, van der Giesen F, Meichtry A, Walker B, Van Gaalen F, Goekoop-Ruitermans YPM, et al. The perspective of people with axial spondyloarthritis regarding physiotherapy: room for the implementation of a more active approach. Rheumatol Adv Pract. 2019;3:1-10.

21. Niedermann K, Nast I, Ciurea A, Vliet Vlieland T, van Bodegom-Vos L. Barriers and facilitators of vigorous cardiorespiratory training in axia Spondyloarthritis: surveys among patients, physiotherapists, rheumatologists. Arthritis Care Res. 2018;71:839-51.

22. Pinnock H, Barwick M, Carpenter CR, Eldridge S, Grandes G, Griffiths CJ, et al. Standards for reporting implementation studies (StaRI) statement. BMJ. 2017;356:16795.

23. Proctor EK, Powell BJ, McMillen JC. Implementation strategies: recommendations for specifying and reporting. Implement Sci. 2013;8:139.

24. Curran GM, Bauer M, Mittman B, Pyne JM, Stetler C. Effectiveness-implementation hybrid designs: combining elements of clinical effectiveness and implementation research to enhance public health impact. Med Care. 2012;50(3):217-26.

25. Buchi S, Buddeberg C, Klaghofer R, Russi EW, Brandli O, Schlosser C, et al. Preliminary validation of PRISM (pictorial representation of illness and self measure) - a brief method to assess suffering. Psychother Psychosom. 2002;71(6):333-41.

26. Miller WR, Rollnick S. Motivational interviewing. Helping people change. 3rd ed. New York: Guilford Publications; 2012

27. Buchi S, Sensky T. PRISM: pictorial representation of illness and self measure. A brief nonverbal measure of illness impact and therapeutic aid in psychosomatic medicine. Psychosomatics. 1999;40(4):314-20.

28. Niedermann K, Buchi S, Ciurea A, Kubli R, Steurer-Stey C, Villiger PM, et al. Six and 12 months' effects of individual joint protection education in people with rheumatoid arthritis: a randomized controlled trial. Scand J Occup Ther. 2012;19(4):360-9.

29. Scherer SA, Noteboom JT, Flynn TW. Cardiovascular assessment in the orthopaedic practice setting. J Orthop Sports Phys Ther. 2005;35(11):730-7.

30. Rogers E. Diffusion of innovations. New York: Simon\&Schuster Ltd; 2003.

31. Prochaska JO, Velicer WF. The transtheoretical model of health behavior change. Am J Health Promot. 1997:12(1):38-48.

32. Colley RC, Butler G, Garriguet D, Prince SA, Roberts KC. Comparison of self-reported and accelerometer-measured physical activity in Canadian adults. Health Rep. 2018;29(12):3-15.

33. Mercer K, Li M, Giangregorio L, Burns C, Grindrod K. Behavior change techniques present in wearable activity trackers: a critical analysis. Jmir Mhealth Uhealth. 2016;4(2):615-23. 
34. Gell NM, Grover KW, Savard L, Dittus K. Outcomes of a text message, Fitbit, and coaching intervention on physical activity maintenance among cancer survivors: a randomized control pilot trial. J Cancer Surviv. 2020;14(1):80-8.

35. Arvidsson D, Fridoltsson J, Borjesson M. Measurement of physical activity in clinical practice using accelerometers. J Intern Med. 2019;286(2):137-53.

36. Dowd KP, Szeklicki R, Minetto MA, Murphy MH, Polito A, Ghigo E, et al. A systematic literature review of reviews on techniques for physical activity measurement in adults: a DEDIPAC study. Int J Behav Nutr Phys. 2018. https://doi.org/10.1186/s12966-017-0636-2.

37. Hagstromer M, Franzen E. The importance of physical activity and health for physical therapy. Phys Ther Rev. 2017;22(3):1-8.

38. Kunstler B, Fuller R, Pervan S, Merolli M. Australian adults expect physiotherapists to provide physical activity advice: a survey. J Physiother. 2019;65:230-6.

39. Shirley D, van der Ploeg HP, Bauman AE. Physical activity promotion in the physical therapy setting: perspectives from practitioners and students. Phys Ther. 2010;90(9):1311-22.

40. Lowe A, Littlewood C, McLean S, Kilner K. Physiotherapy and physical activity: a cross-sectional survey exploring physical activity promotion, knowledge of physical activity guidelines and the physical activity habits of UK physiotherapists. BMJ Open Sport Exerc Med. 2017;3(1):e000290.

41. Neil-Sztramko S, Ghayyur A, Edwards J, Campbell KL. Physical activity levels of physiotherapists across practice settings: a cross-sectional comparison using self-report questionnaire and accelerometer measures. Physiother Can. 2016;69(2):1-9.

42. de Bruin M, Kok G, Schaalma H, Hospers H. Coding manual for behavioral change techniques. 2007

43. Kunstler BE, Cook JL, Freene N, Finch CF, Kemp JL, O'Halloran PD, et al. Physiotherapists use a small number of behaviour change techniques when promoting physical activity: a systematic review comparing experimental and observational studies. J Sci Med Sport. 2018;21(6):609-15.

44. Hilberdink B, van der Giesen F, Vliet Vlieland T, Nijkamp M, van Weely S. How to optimize exercise behavior in axial spondyloarthritis? Results of an intervention mapping study. Patient Educ Couns. 2020;103(5):952-9.

45. Metsios GS, Fenton SA, Moe HR, van der Esch M, van Zanten JV, Koutedakis $Y$, et al. Implementation of physical activity into routine clinical practice in rheumatic musculoskeletal disease: the IMPACT-RMD study protocol and rationale. Mediterr J Rheumatol. 2019;30(4):231-6.

46. Sveaas SH, Dagfinrud H, Johansen MW, Pedersen E, Wold OM, Bilberg A. longterm effect on leisure time physical activity level in individuals with axial spondyloarthritis: secondary analysis of a randomized controlled trial. J Rheumatol. 2019;47:1189-97.

47. Koorts H, Eakin E, Estabrooks P, Timperio A, Salmon J, Bauman A. Implementation and scale up of population physical activity interventions for clinical and community settings: the PRACTIS guide. Int J Behav Nutr Phys Act. 2018;15(1):51.

48. Zullig LL. Integrating the implemenation science team over the lifecycle of an intervention (manuscript in preparation, presented IMPACT Basel February 2021). 2021.

49. O'Keeffe M, Hayes A, McCreesh K, Purtill H, O'Sullivan K. Are group-based and individual physiotherapy exercise programmes equally effective for musculoskeletal conditions? A systematic review and meta-analysis. $\mathrm{Br} J$ Sports Med. 2017:51(2):126-32.

50. Knittle K, Nurmi J, Crutzen R, Hankonen N, Beattie M, Dombrowski SU. How can interventions increase motivation for physical activity? A systematic review and meta-analysis. Health Psychol Rev. 2018;12(3):211-30.

51. Blixt L, Solbraekke KN. The significance of social rules in group training sessions. Disabil Rehabilit. 2017;39(24):2477-83.

52. Bandura A. Social learning theory. Prentice Hall: University of Michigan; 1977.

53. Rusman T, van Vollenhoven RF, van der Horst-Bruinsma IE. Gender differences in axial spondyloarthritis: women are not so lucky. Curr Rheumatol Rep. 2018;20(6):35.

54. Hilberdink B, van der Giesen F, Vliet Vlieland T, van Gaalen F, van Weely S. Supervised group exercise in axial spondyloarthritis: patients' satisfaction and perspective on evidence-based enhancements. Arthritis Care Res (Hoboken). 2020;72(6):829-37.

55. Sveaas SH, Smedslund G, Hagen KB, Dagfinrud H. Effect of cardiorespiratory and strength exercises on disease activity in patients with inflammatory rheumatic diseases: a systematic review and meta-analysis. Br J Sports Med. 2017;51(14):1065-72.

56. Niedermann K, Sidelnikov E, Muggli C, Dagfinrud H, Hermann M, Tamborrini G, Ciurea A, Bischoff-Ferrari H. Effect of cardiovascular training on fitness and perceived disease activity in people with ankylosing spondylitis. Arthritis Care Res. 2013;65(11):1844-52.

57. Saracoglu I, Kurt G, Okur EO, Afsar E, Seyyar GK, Calik BB, Taspinar F. The effectiveness of specific exercise types on cardiopulmonary functions in patients with ankylosing spondylitis: a systematic review. Rheumatol Int. 2017;37(3):409-21.

58. Boniface G, Gandhi V, Norris M, Williamson E, Kirtley S, O'Connell NE. A systematic review exploring the evidence reported to underpin exercise dose in clinical trials of rheumatoid arthritis. Rheumatology (Oxford). 2020:59:3147-57.

59. Davergne T, Tekaya R, Deprouw C, Sellam J, Tournadre A, Mitrovic S, et al. To apply the recent EULAR recommendations, more knowledge on adherence patterns to medication and to physical activity is needed. Joint Bone Spine. 2021:88(2):105137.

60. Carroll C, Patterson M, Wood S, Booth A, Rick J, Balain S. A conceptual framework for implementation fidelity. Implement Sci. 2007. https://doi. org/10.1186/1748-5908-2-40.

61. Bennett H, Parfitt G, Davison K, Eston R. Validity of submaximal step tests to estimate maximal oxygen uptake in healthy adults. Sports Med. 2016:46(5):737-50.

62. Buckley JP, Sim J, Eston RG, Hession R, Fox R. Reliability and validity of measures taken during the Chester step test to predict aerobic power and to prescribe aerobic exercise. Br J Sports Med. 2004;38(2):197-205.

63. BASPO BfS. Manual leistungsdiagnostik. 2015.

64. Rausch AK, Baltisberger P, Meichtry A, Topalidis B, Ciurea A, Vliet Vlieland TPM, et al. Reliability of an adapted core strength endurance test battery in individuals with axial spondylarthritis. Clin Rheumatol. 2020:40:1353-60

65. Springer BA, Marin R, Cyhan T, Roberts H, Gill NW. Normative values for the unipedal stance test with eyes open and closed. J Geriatr Phys Ther. 2007:30(1):8-15.

66. Sieper J, Rudwaleit M, Baraliakos X, Brandt J, Braun J, Burgos-Vargas $R$, et al. The assessment of spondyloarthritis international society (ASAS) handbook: a guide to assess spondyloarthritis. Ann Rheum Dis. 2009;68(Suppl 2):ii1-44.

67. Hallal PC, Victora CG. Reliability and validity of the international physical activity questionnaire (IPAQ). Med Sci Sports Exerc. 2004;36(3):556.

68. Jones SD, Steiner A, Garrett SL, Calin A. The bath ankylosing spondylitis patient global score (BAS-G). Br J Rheumatol. 1996;35(1):66-71.

69. Kiltz U, van der Heijde D, Boonen A, Braun J. The ASAS Health Index (ASAS $\mathrm{HI}$ ) — a new tool to assess the health status of patients with spondyloarthritis. Clin Exp Rheumatol. 2014;32(5 Suppl 85):S-105-S-108.

70. Graf J, Claes D, Greiner W. The German version of the EuroQol questionnaire. Z Gesundh Wiss. 1998;6:3-20.

\section{Publisher's Note}

Springer Nature remains neutral with regard to jurisdictional claims in published maps and institutional affiliations.

Ready to submit your research? Choose BMC and benefit from

- fast, convenient online submission

- thorough peer review by experienced researchers in your field

- rapid publication on acceptance

- support for research data, including large and complex data types

- gold Open Access which fosters wider collaboration and increased citations

- maximum visibility for your research: over 100M website views per year

At BMC, research is always in progress.

Learn more biomedcentral.com/submissions 